CLINICAL STUDY

\title{
Circulating glucocorticoid bioactivity and serum cortisol concentrations in premature infants: the influence of exogenous glucocorticoids and clinical factors
}

\author{
Päivi Nykänen ${ }^{1,2}$, Taneli Raivio ${ }^{3,4}$, Kirsti Heinonen ${ }^{1}$, Olli A Jänne ${ }^{4,5}$ and Raimo Voutilainen ${ }^{1,6}$ \\ ${ }^{1}$ Department of Paediatrics, University of Kuopio, FI-70211 Kuopio, Finland, ${ }^{2}$ Department of Paediatrics, Mikkeli Central Hospital, Mikkeli, Finland, \\ ${ }^{3}$ Hospital for Children and Adolescents, ${ }^{4}$ Biomedicum Helsinki, Institute of Biomedicine and ${ }^{5}$ Department of Clinical Chemistry, FI-OOO14 Helsinki, \\ Finland and ${ }^{6}$ Department of Paediatrics, Kuopio University Hospital, FI-70211 Kuopio, Finland \\ (Correspondence should be addressed to R Voutilainen who is now at Department of Paediatrics, Kuopio University Hospital, PO Box 1777, FI-70211 \\ Kuopio, Finland; Email: raimo.voutilainen@uku.fi)
}

\begin{abstract}
Objective: Glucocorticoids are widely used before preterm delivery and in preterm infants may bear serious adverse effects. Better knowledge about the circulating glucocorticoid milieu after glucocorticoid treatment could improve treatment modalities. Therefore, we investigated the influence of exogenous glucocorticoids and clinical factors on serum cortisol (F) levels and circulating glucocorticoid bioactivity (GBA) in preterm infants.

Design: Eighty-nine infants (gestational age (GA) 23.6-33.1 weeks at birth) were enrolled in a prospective cohort study in two tertiary neonatal centres.

Methods: Cord, day of birth (D0), fourth day (D4) and 36 weeks postmenstrual age serum F and GBA levels were measured.

Results: The cord GBA was 5.8-fold and DO GBA 2.3-fold higher in the infants exposed to antenatal steroids within $12 \mathrm{~h}$ before birth when compared with those unexposed or exposed $>7$ days before birth (95\% CI 3.8-8.6; $P<0.0001$, and 1.8-3.0; $P<0.0001$ respectively). In the infants treated with early postnatal dexamethasone, D4 GBA was 1.7 -fold $(1.3-2.2 ; P<0.0005)$ higher when compared with levels in the infants without this treatment. Clinical factors indicating perinatal distress, such as Apgar scores $<7$ and low GA, were associated with higher cord, D0 and D4 serum F levels.

Conclusions: Both ante- and postnatally administered glucocorticoids increase circulating GBA not attributable to endogenous F. Perinatal distress and preceding glucocorticoid treatment need to be taken into account when circulating glucocorticoid milieu is evaluated in preterm infants. The GBA assay may prove to be a useful instrument in the development of new glucocorticoid treatment strategies.
\end{abstract}

European Journal of Endocrinology 156 577-583

\section{Introduction}

Glucocorticoids are widely used before preterm delivery and in preterm infants (1). Antenatally administered betamethasone reduces perinatal mortality and morbidity (2), and postnatal dexamethasone (Dx) temporarily improves respiratory function and expedites extubation (3). However, early postnatal use of Dx may bear adverse effects, including those related to brain development (4-6). The most detrimental side effects may be partly due to steroid dosing, and/or to varying pharmacokinetics of glucocorticoids in preterm infants. For example, clearance of Dx is dependent on gestational age (GA), being slowest in the tiniest preterms (7). Additional complexity arises from different biological activities of the steroids in clinical use. Thus, knowledge about how the circulating glucocorticoid milieu is influenced by exogenous glucocorticoids could improve treatment modalities.

We have recently developed a recombinant cell bioassay, based on the expression of human glucocorticoid receptor together with an appropriate reporter gene in mammalian cells (8). The assay measures glucocorticoid bioactivity (GBA) brought about by both endogenous and exogenous glucocorticoids, is capable of measuring GBA in a small amount of serum $(10 \mu \mathrm{l})$, and thus is suitable for investigating GBA even in the most preterm infants (9).

In the current work, we analysed the influence of clinical factors and various glucocorticoid treatment modalities on cortisol (F) concentrations and GBA measured in the cord and preterm infants' serum postnatally. We anticipate that our results prove useful when optimising glucocorticoid treatment in preterm infants. 


\section{Subjects and methods}

\section{Subjects}

The study population consisted of preterm infants enrolled originally in a prospective cohort study to investigate the association of adrenocortical function with the outcome. The infants were born in Kuopio or Oulu University Hospitals between October 1998 and September 2001. The entry criteria to the study were 1) prematurity (GA $<34$ weeks at birth), 2) need for mechanical ventilation during the first day of life, and 3) absence of life-threatening congenital or chromosomal anomalies. The study design was approved by the Research Ethics Committees of both units. Written informed consent was obtained from the parents before the study.

Chorioamnionitis and pre-eclampsia were diagnosed based on clinical criteria by the attending obstetrician. The GA at birth was calculated from the last menstruation of the mother or by ultrasound examination of the foetus at 11 weeks postmenstrual age (PMA). Birth weight (BW) was recorded and the criterion for small gestational age (SGA) was BW $\leq-2$ s.D. according to the Finnish intrauterine growth charts (10). The mode of delivery (vaginal or caesarean section), gender and single or multiple birth were recorded. The Apgar scores were assessed at $1 \mathrm{~min}$ and a score below seven was considered low and an indicator of perinatal distress. The criterion for the diagnosis of bronchopulmonary dysplasia (BPD) was oxygen dependency at 36 weeks PMA.

\section{Glucocorticoid treatments}

Antenatal steroid treatment (ANS) consisted of betamethasone $12 \mathrm{mg}$ twice or Dx $15 \mathrm{mg}$ and $10 \mathrm{mg}$ given to the mothers intramuscularly on 2 consecutive days when a preterm delivery had been anticipated. Additional ANS courses had been given at the discretion of the attending obstetrician. The time interval between the last ANS and birth was recorded in four categories: 1) $<12 \mathrm{~h}, 2) 12-72 \mathrm{~h}, 3)$ 3-7 days and 4) more than 7 days or no ANS. None of the mothers had received regular glucocorticoid therapy during the pregnancy.

The effect of postnatal Dx treatment on $\mathrm{F}$ and GBA levels was analysed at two different time points: on day 4 (D4) after 'early Dx' and at 36 weeks PMA after ' 36 weeks Dx'. The 'early Dx' course (median duration 2 (range 1-4) days) was used as an attempt to prevent BPD (11). The '36 weeks Dx' included 'early Dx' and later Dx treatments for infants with severe respiratory distress syndrome (RDS) or prolonged need for mechanical ventilation. It was started between days 1-35 and given for median 8 (range 1-35) days. The dose of Dx used was $0.25 \mathrm{mg} / \mathrm{kg}$ twice a day intravenously. Hydrocortisone $5 \mathrm{mg} / \mathrm{kg}$ per day was used to treat hypoglycaemia resistant to intravenous glucose administration. Adrenal insufficiency after prolonged Dx treatment was supplemented with hydrocortisone $<1 \mathrm{mg} / \mathrm{kg}$ per day. Budesonide 500-2000 $\mu \mathrm{g} /$ day to treat BPD was administered with Spira Module 2 nebuliser (08TSM002, Spira OY, Hämeenlinna, Finland).

\section{Laboratory measurements}

Serum samples for basal F and GBA measurements were collected from mixed cord blood and venous or arterial blood on the day of birth (D0, median age 4 , range 0-14 h), day 4 (D4, median age 4 , range 2-7 days) and at 36 weeks (median age 36, range 33-37 weeks) PMA. Between birth and D0 sampling, none of the newborns were given Dx or hydrocortisone. The D4 and 36 weeks serum samples were collected at least $48 \mathrm{~h}$ after the last Dx dose. All serum samples were stored at $-20{ }^{\circ} \mathrm{C}$ until analysed.

Serum F was analysed by the Immulite 2000 chemiluminescent enzyme immunoassay (EIA; Diagnostic Products Corporation, Los Angeles, CA, USA). The intra- and interassay coefficients of variation (reported by the manufacturer) were below 7.5 and $9.5 \%$ respectively in the concentration range of 91-855 nmol/l. The cross-reactivity of the $\mathrm{F}$ antiserum was $7.5 \%$ for corticosterone, $1.6 \%$ for 11 -deoxycortisol, $1.0 \%$ for cortisone and $0.2 \%$ for $17 \mathrm{OH}$-progesterone and 21-deoxycortisone. There was no detectable crossreactivity for DHEAS, progesterone or Dx. The lowest reported $\mathrm{F}$ value was $28 \mathrm{nmol} / \mathrm{l}$. GBA was measured directly from $10 \mu \mathrm{l}$ serum samples using the recombinant cell bioassay in which COS-1 cells are transfected with expression vectors encoding the human glucocorticoid receptor and the nuclear receptor coregulator androgen receptor-interacting protein 3 (ARIP3), together with an appropriate reporter gene (luciferase), as described previously (8). The lowest reported value was $15.6 \mathrm{nmol} / \mathrm{l} \mathrm{F}$ equivalents in foetal calf serum.

\section{Data analysis}

Data were analysed using the statistical program SPSS for Windows, Release 11.5.1 (SPSS Inc., Chicago, IL, USA). Only the serum samples with both F and GBA measurements available were included in the analyses. The $\mathrm{F}$ levels below the detection limit $(<28 \mathrm{nmol} / \mathrm{l})$ were recorded in the analyses as $27 \mathrm{nmol} / \mathrm{l}$ and GBA levels $<15.6 \mathrm{nmol} / \mathrm{l} \mathrm{F}$ equivalents as 15.0. Based on previous studies $(9,12)$, control groups not expected to have any exogenous glucocorticoid activity were formed from the total study group separately for each sampling time. The control groups consisted of infants who had received ANS more than 7 days before birth or no ANS (cord, D0 and D4 control groups) and had not received any postnatal glucocorticoid therapy (D4 and 36 weeks control groups).

As all $\mathrm{F}$ and GBA values followed right-skewed distribution, logarithmically transformed values were used in linear regression models investigating the role of 
different clinical variables (listed in Table 1) in explaining the variation observed in serum $\mathrm{F}$ and GBA. To allow for possible non-linear effects, the time between the last ANS dose and birth was divided into four categories $(<12 \mathrm{~h}, 12-72 \mathrm{~h}, 3-7$ days and $>7$ days or no ANS); the first three subsequently served as dummy variables in the regression analyses when compared with the control group. Thus, the regression coefficients represent fold-change of the dependent factor caused by a unit change in the independent factor. To make interpretation easier, the coefficients reported were back-transformed by inversed logarithmic change. In addition, Spearman's rank correlation analysis was used to investigate the strength of nonlinear relationships between the two variables. In comparisons between multiple groups, Kruskall-Wallis test and between two groups, Mann-Whitney test was used (with Bonferroni correction for multiple comparisons). $P<0.05$ was accepted to indicate statistical significance.

\section{Results}

Eighty-nine infants were enrolled in the study. The clinical characteristics of the study group are summarised in Table 1. Nine infants $(10 \%)$ died and 26 (30\%) contracted BPD before 36 weeks PMA. The total

Table 1 The baseline characteristics and glucocorticoid treatments of 89 preterm infants.

\begin{tabular}{|c|c|c|}
\hline \multicolumn{2}{|l|}{ Gestational age (GA) } & $\begin{array}{l}28.2(23.6-33.1)^{a} \\
\text { weeks }\end{array}$ \\
\hline \multicolumn{2}{|l|}{ Clinical chorioamnionitis } & $27(30 \%)$ \\
\hline \multicolumn{2}{|l|}{ Pre-eclampsia } & $24(27 \%)$ \\
\hline \multicolumn{2}{|l|}{ Caesarean section } & $65(73 \%)$ \\
\hline \multicolumn{2}{|l|}{ Birth weight (BW) } & $1059(455-2210)^{\mathrm{a}} \mathrm{g}$ \\
\hline \multicolumn{2}{|l|}{$\begin{array}{l}\text { Small for gestational age } \\
\text { (BW }<-2 \text { S.D.) }\end{array}$} & $21(24 \%)$ \\
\hline \multicolumn{2}{|l|}{ Singleton } & $58(65 \%)$ \\
\hline \multicolumn{2}{|l|}{ Boys } & $44(49 \%)$ \\
\hline \multirow{4}{*}{$\begin{array}{l}\text { Time since last antenatal } \\
\text { steroid (ANS) }\end{array}$} & $<12 \mathrm{~h}$ & $15(17 \%)$ \\
\hline & $12-72 \mathrm{~h}$ & $28(31 \%)$ \\
\hline & 3-7 days & $25(28 \%)$ \\
\hline & $>7$ days or no & $21(24 \%)$ \\
\hline \multirow[t]{5}{*}{ ANS courses } & 0 & $6(7 \%)$ \\
\hline & 1 & $71(80 \%)$ \\
\hline & 2 & $4(4 \%)$ \\
\hline & 3 & $7(8 \%)$ \\
\hline & 4 & $1(1 \%)$ \\
\hline \multirow{2}{*}{\multicolumn{2}{|c|}{$\begin{array}{l}\text { Early dexamethasone } \\
\text { treatment (Dx, before D4) } \\
\text { Dx before } 36 \text { weeks } \\
\text { postmenstrual age } \\
\text { (PMA) }\end{array}$}} & $17(19 \%)$ \\
\hline & & \\
\hline \multirow{2}{*}{\multicolumn{2}{|c|}{$\begin{array}{l}\text { Dx treated } \\
\text { Number of days on Dx } \\
\text { before } 36 \text { weeks PMA } \\
\text { (days) }\end{array}$}} & 39 (44\%) \\
\hline & & $8(1-35)^{b}$ \\
\hline \multicolumn{2}{|l|}{ Inhaled budesonide } & $43(48 \%)$ \\
\hline
\end{tabular}

number of available cord, D0 (first day), D4 (median 4 th, range 2-7 days) and 36 (range 33-37) weeks serum $F$ and GBA pairs was 42, 79, 63 and 68 respectively. The serum samples of the six infants who were treated with high dose of hydrocortisone on D4 were excluded from the D4 analyses. The median (range) serum $\mathrm{F}$ and GBA concentrations and the correlation coefficients between $F$ and GBA in the infants without ongoing or recent glucocorticoid treatment are shown in Table 2. The GBA levels were $25-29 \%$ of the respective $\mathrm{F}$ levels and these variables displayed strong positive correlation with each other. The 36 weeks serum $\mathrm{F}$ was $<28 \mathrm{nmol} / \mathrm{l}$ in two infants and $<55 \mathrm{nmol} / \mathrm{l}$ in eight infants without any postnatal steroid treatment. They all also had unmeasurable GBA levels ( $<15.6 \mathrm{nmol} / \mathrm{l} \mathrm{F}$ equivalents).

\section{Cord and DO serum F and GBA}

The cord and DO GBA levels were significantly higher in the infants exposed to ANS within $12 \mathrm{~h}$ before birth than in those exposed $>7$ days before birth or not at all (Fig. 1). On the other hand, the cord and DO F levels tended to be lower in the infants with recent exposure to ANS than in those with remote or no exposure $(P=0.12$ and $P=0.20$ respectively). Cord $F$ level was 1.7-fold (95\% CI 1.1-2.6; $P<0.04$ ) and DO serum F level 2.6-fold (95\% CI 1.7-4.0; $P<0.0001)$ higher in infants with Apgar scores $<7$ compared with those with Apgar $\geq 7$, when the model was adjusted for timing of ANS, number of ANS courses, mode of delivery and GA. These factors explained approximately 37 and $26 \%$ of the variation observed in cord and DO F levels respectively. The timing and number of ANS courses were the only significant determinants of the cord GBA levels (Table 3A), whereas the timing of ANS and serum F levels were significant determinants of DO GBA levels (Table 3B).

\section{D4 serum F and GBA}

The D4 GBA levels were higher in the infants treated with the 'early Dx' treatment than in controls (Fig. 2),

Table 2 The median (range) serum cortisol (F) concentrations, glucocorticoid bioactivity (GBA) levels and Spearman correlation coefficients $(r)$ between the respective serum $F$ and GBA values in the infants without ongoing or recent glucocorticoid treatment.

\begin{tabular}{|c|c|c|c|c|}
\hline $\begin{array}{l}\text { Sampling } \\
\text { time }\end{array}$ & $n$ & $\mathbf{F}(\mathrm{nmol} / \mathrm{l})$ & $\begin{array}{c}\text { GBA (nmol/l } \\
\text { cortisol } \\
\text { equivalents) }\end{array}$ & $r$ \\
\hline Cord & 12 & $86(51-147)$ & $23(<15.6-44)$ & $0.625^{*}$ \\
\hline $\mathrm{DO}^{\mathrm{a}}$ & 18 & $453(50-2307)$ & $127(<15.6-315)$ & $0.979^{\dagger}$ \\
\hline $\mathrm{D} 4^{\mathrm{a}}$ & 12 & $175(45-340)$ & $50(16-96)$ & $0.958^{\dagger}$ \\
\hline 36 weeks $^{a}$ & 27 & $142(<28-394)$ & $35(<15.6-135)$ & $0.876^{\dagger}$ \\
\hline
\end{tabular}



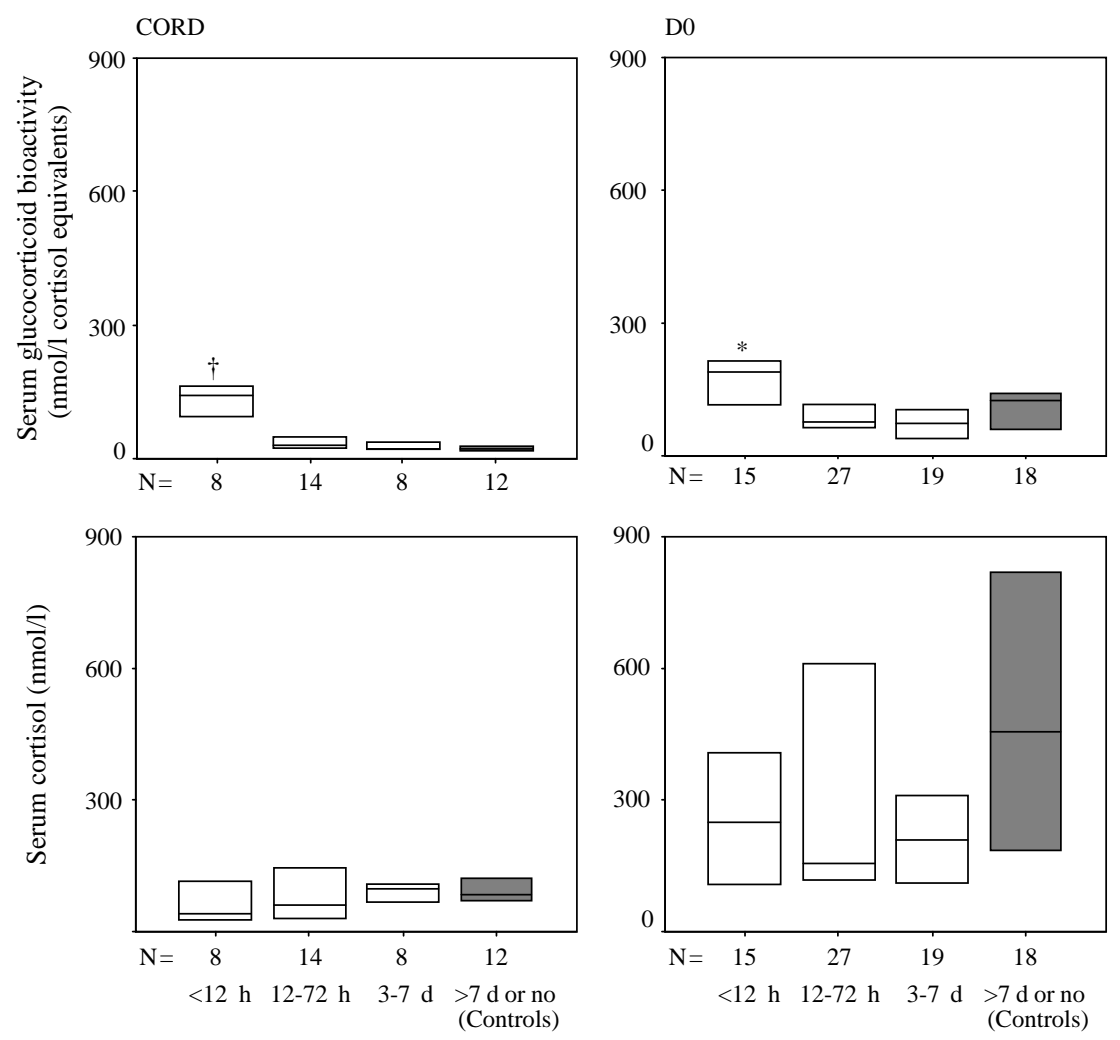

Figure 1 The cord and first day (D0) serum glucocorticoid bioactivity (GBA) and cortisol levels (medians, 25th and 75th percentiles) in premature infants grouped according to the time since the last antenatal steroid (ANS) dose before birth ( $<12 \mathrm{~h}, 12-72 \mathrm{~h}, 3-7$ days (open columns) and $>7$ days or no ANS as controls (filled columns)). The median cord and DO serum GBA were significantly higher in the infants treated with ANS $<12 \mathrm{~h}$ before birth compared with the controls $\left({ }^{\dagger} P<0.0001\right.$; ${ }^{\star} P<0.05$; Kruskall-Wallis test followed by MannWhitney test with Bonferroni correction

Time since the last antenatal steroid dose

Time since the last antenatal steroid dose for multiple comparisons).

Table 3 Factors contributing to the cord (A), first day (D0; B) and fourth day (D4; C) circulating glucocorticoid bioactivity (GBA) in premature infants in multiple linear regression models.

\begin{tabular}{|c|c|c|c|c|c|c|}
\hline \multirow[b]{2}{*}{ A cord $(n=42)$} & \multicolumn{3}{|c|}{ Time since the last ANS dose before birth } & \multirow[b]{2}{*}{$\begin{array}{l}\text { Number of } \\
\text { ANS courses }\end{array}$} & \multirow[b]{2}{*}{ Apgar $<7$} & \multirow[b]{2}{*}{$\begin{array}{l}\text { Log of cord serum } \\
\text { cortisol }(\mathrm{nmol} / \mathrm{l})\end{array}$} \\
\hline & $0-12 \mathrm{~h}$ & $12-72 \mathrm{~h}$ & 3-7 days & & & \\
\hline \multirow{3}{*}{$\begin{array}{l}\text { B coefficient }(95 \% \mathrm{Cl}) \\
P \text { value } \\
R^{2}=0.78\end{array}$} & $5.8(3.8-8.6)$ & $1.4(0.94-2.0)$ & $1.1(0.69-1.6)$ & $0.78(0.62-1.0)$ & $1.2(0.87-1.6)$ & $1.5(0.85-2.5)$ \\
\hline & $<0.0001$ & 0.10 & 0.79 & 0.03 & 0.27 & 0.16 \\
\hline & \multicolumn{3}{|c|}{ Time since the last ANS dose before birth ${ }^{a}$} & & & \\
\hline B Do $(n=79)$ & $0-12 \mathrm{~h}$ & $12-72 \mathrm{~h}$ & 3-7 days & $\begin{array}{l}\text { Number of } \\
\text { ANS courses }\end{array}$ & Apgar $<7$ & $\begin{array}{c}\text { Log of DO serum } \\
\text { cortisol }(\mathrm{nmol} / \mathrm{l})\end{array}$ \\
\hline \multirow{3}{*}{$\begin{array}{l}\text { B coefficient }(95 \% \mathrm{Cl}) \\
P \text { value } \\
R^{2}=0.78\end{array}$} & $2.3(1.8-3.0)$ & $1.3(1.0-1.6)$ & $0.93(0.73-1.2)$ & $0.89(0.80-1.0)$ & $1.0(0.82-1.2)$ & $3.6(2.9-4.4)$ \\
\hline & \multicolumn{4}{|c|}{ Time since the last ANS dose before birth ${ }^{a}$} & & \\
\hline & $0-12 \mathrm{~h}$ & \multicolumn{2}{|c|}{$12-72 \mathrm{~h}$} & -7 days & $\begin{array}{l}\text { 'Early Dx' } \\
\text { treatment }\end{array}$ & $\begin{array}{c}\text { Log of D4 serum } \\
\text { cortisol }(\mathrm{nmol} / \mathrm{l})\end{array}$ \\
\hline B coefficient $(95 \% \mathrm{Cl})$ & $1.3(0.96-1.7)$ & \multirow{2}{*}{\multicolumn{2}{|c|}{$\begin{array}{c}1.1(0.81-1.4) \\
0.59\end{array}$}} & $(0.81-1.4)$ & $1.7(1.3-2.2)$ & $4.5(3.2-6.2)$ \\
\hline $\begin{array}{l}P \text { value } \\
R^{2}=0.74\end{array}$ & 0.09 & & & 0.66 & $<0.0005$ & $<0.0001$ \\
\hline
\end{tabular}



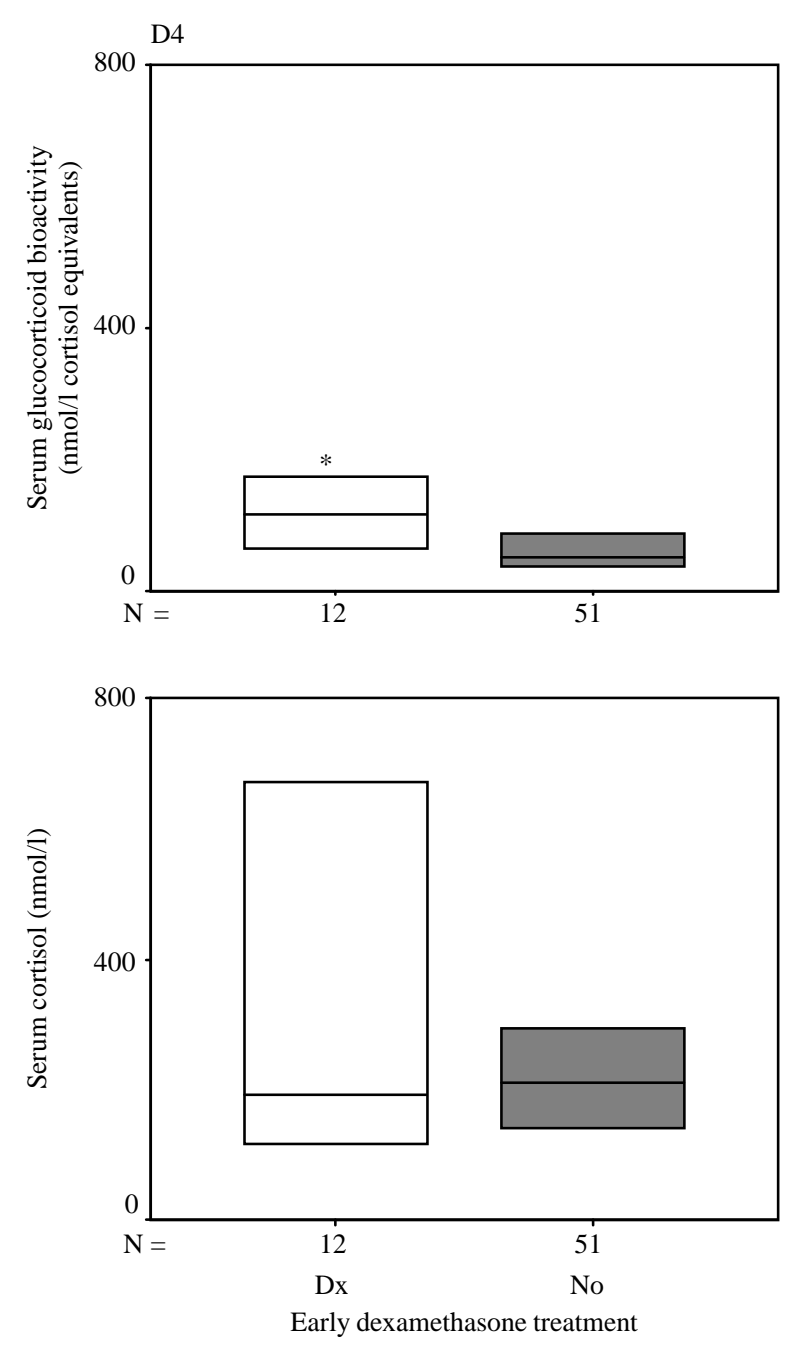

Figure 2 The fourth day (D4) serum glucocorticoid bioactivity (GBA) and cortisol levels (medians, 25th and 75th percentiles) in premature infants treated with an early short-term dexamethasone course (Dx, open columns) compared with those without this treatment (No, filled columns). The median D4 serum GBA was significantly higher in the Dx treated than in the non-treated infants $\left({ }^{*} P<0.005\right.$, Mann-Whitney test).

but no such difference was found in D4 serum F levels. In the multiple linear regression analysis, 1 week reduction in GA was associated with 1.1 -fold $(95 \% \mathrm{CI}$ 1.0-1.2, $P<0.05)$ D4 F levels, when the model was adjusted for the timing of ANS and the 'early Dx' treatment $\left(R^{2}=0.29\right)$. The 'early Dx' treatment and the D4 serum F levels were the only significant contributors to the D4 GBA levels (Table 3C).

\section{Thirty-six weeks serum F and GBA}

The median 36 weeks serum $\mathrm{F}$ was significantly lower in the Dx-treated infants than in the non-treated infants (43 vs $107 \mathrm{nmol} / \mathrm{l}, P<0.02, n=68$ ) and the median 36 weeks serum GBA had a similar trend (19 vs $22 \mathrm{nmol} / \mathrm{l}$ cortisol equivalents, $P=0.12$ ). In addition, the duration of the ' 36 weeks Dx' treatment correlated negatively with the 36 weeks serum $\mathrm{F}$ levels $(r=-0.301$, $P<0.02$ ) and tended to correlate with the 36 weeks serum GBA levels $(r=-0.211, P=0.08)$. Similarly, the inhaled budesonide treatment preceding 36 weeks correlated negatively with the 36 weeks serum $\mathrm{F}$ and GBA levels (data not shown). Because numerous study subjects had received both inhaled budesonide and ' 36 weeks Dx' therapy, we were unable to distinguish the effects of these two steroids on serum GBA and F levels.

\section{Discussion}

To our knowledge, this is the first study to measure circulating GBA levels in preterm infants after birth. In preterm infants not recently exposed to exogenous glucocorticoids, we found a strong correlation between serum $\mathrm{F}$ and GBA levels at all time points investigated postnatally. This is in concordance with two previous studies, in which serum $\mathrm{F}$ and GBA levels were measured in newborns and children $(8,9)$. After some reports had linked the use of early postnatal Dx in preterm infants to suboptimal long-term brain development (4-6), new strategies in glucocorticoid use have been developed. For example, the recently introduced early hydrocortisone prophylaxis possibly increases survival without BPD (13, 14). However, an increased risk of gastrointestinal perforations associated with high endogenous $\mathrm{F}$ levels was noted (14). The bioassay for serum GBA, employed in the current work, provides a novel means to evaluate the effects of glucocorticoid treatment on circulating glucocorticoid milieu, and may thus pave the way for safer therapy of infants born prematurely.

Preterm infants treated with ANS within the $12 \mathrm{~h}$ before birth displayed the highest serum GBA levels. This is in agreement with previous studies $(9,12)$ and underlines the fact that betamethasone and Dx are poor substrates for the 11ß-hydroxysteroid dehydrogenase type 2 enzyme, the metabolic barrier protecting the foetus against high maternal $\mathrm{F}$ concentrations (15). The lack of significant differences in the cord and D0 serum F levels between the different ANS treatment groups is at least partly explained by the small number of infants without ANS treatment making the type two statistical error possible. However, the tendency to lower F levels in the infants treated with ANS within $72 \mathrm{~h}$ before birth is in concordance with previous studies $(9,12,16-18)$. The association of decreased cord and DO serum GBA with the increasing number of ANS courses is probably mediated by the suppression of the respective $\mathrm{F}$ levels after multiple ANS courses administered several days before delivery $(17,19)$.

Treatment of a preterm infant with Dx for a week or longer is associated with suppression of the hypothalamo-pituitary-adrenal (HPA) axis (20-24), and therefore shorter Dx courses have been introduced to 
treat severe RDS and to wean the infant from mechanical ventilation $(11,17,25-28)$. In some studies, even 2-5 days of $\mathrm{Dx}$ treatment has been shown to suppress $\mathrm{F}$ levels $(17,27)$, although this is not a constant finding in all studies (28). In our work, GBA levels were still high $48 \mathrm{~h}$ after 'early Dx' treatment, a finding probably reflecting the long halftime of $\mathrm{Dx}$ in the most premature infants (7). In contrast, following a longer Dx course both F and GBA levels at 36 weeks PMA were suppressed, probably reflecting central suppression of the HPA axis. The lack of significant correlation between serum GBA levels at 36 weeks PMA and the duration of such longer Dx courses might be explained by the influence of the ongoing inhaled budesonide treatment (8).

Low Apgar scores and GA are associated with increased cord, DO and D4 F and GBA levels. This suggests that most preterm infants have functional HPA axis with appropriate capacity to secrete $\mathrm{F}$ in response to distress, as proposed also in previous studies (29-31). However, there may be preterm newborns who have significant adrenocortical insufficiency in relation to their clinical condition during the first days of life (32), and who might benefit from glucocorticoid treatment $(13,14)$. On the other hand, and quite surprisingly, we found several healthy infants whose F and GBA levels at 36 weeks PMA were very low, even without any postnatal glucocorticoid treatment. Thus, one of the future challenges related to optimising glucocorticoid treatment is to find the appropriate serum $\mathrm{F}$ range in premature infants in different degrees of distress.

In conclusion, both ante- and postnatally administered glucocorticoids increase circulating GBA not attributable to endogenous F. The preceding glucocorticoid treatment and the increase in endogenous $\mathrm{F}$ caused by birth-related distress need to be taken into account when evaluating circulating glucocorticoid milieu in preterm infants. The GBA assay may prove to be a useful instrument in the development of new glucocorticoid treatment strategies.

\section{Acknowledgements}

P Nykänen is grateful to Mikkeli Central Hospital, the Finnish Foundation for Paediatric Research and Sigrid Juselius Foundation for financial assistance. The study was also supported by Academy of Finland and Kuopio University Hospital. We thank Prof. Mikko Hallman and Dr Eija Anttila from the Oulu University Hospital for their help in patient recruitment.

\section{References}

1 Grier DG \& Halliday HL. Corticosteroids in the prevention and management of bronchopulmonary dysplasia. Seminars in Neonatology 20038 83-91.
2 Crane J, Armson A, Brunner M, De La Ronde S, Farine D, KeenanLindsay L, Leduc L, Schneider C \& Van Aerde J. Antenatal corticosteroid therapy for fetal maturation. Journal of Obstetrics and Gynaecology Canada 200325 45-52.

3 Grier DG \& Halliday HL. Management of bronchopulmonary dysplasia in infants: guidelines for corticosteroid use. Drugs 2005 65 15-29.

4 O'Shea TM \& Doyle LW. Perinatal glucocorticoid therapy and neurodevelopmental outcome: an epidemiologic perspective. Seminars in Neonatology 20016 293-307.

5 Baud O. Postnatal steroid treatment and brain development. Archives of Disease in Childhood. Fetal and Neonatal Edition 200489 F96-100.

6 Yeh TF, Lin YJ, Lin HC, Huang CC, Hsieh WS, Lin CH \& Tsai CH. Outcomes at school age after postnatal dexamethasone therapy for lung disease of prematurity. New England Journal of Medicine 2004 350 1304-1313.

7 Lugo RA, Nahata MC, Menke JA \& McClead RE Jr. Pharmacokinetics of dexamethasone in premature neonates. European Journal of Clinical Pharmacology 199649 477-483.

8 Raivio T, Palvimo JJ, Kannisto S, Voutilainen R \& Janne OA. Transactivation assay for determination of glucocorticoid bioactivity in human serum. Journal of Clinical Endocrinology and Metabolism 200287 3740-3744.

9 Kajantie E, Raivio T, Janne OA, Hovi P, Dunkel L \& Andersson S. Circulating glucocorticoid bioactivity in the preterm newborn after antenatal betamethasone treatment. Journal of Clinical Endocrinology and Metabolism 200489 3999-4003.

10 Pihkala J, Hakala T, Voutilainen P \& Raivio K. Characteristic of recent fetal growth curves in Finland. Duodecim 1989105 1540-1546.

11 Anttila E, Peltoniemi O, Haumont D, Herting E, ter Horst H, Heinonen K, Kero P, Nykanen P, Oetomo SB \& Hallman M. Early neonatal dexamethasone treatment for prevention of bronchopulmonary dysplasia. Randomised trial and meta-analysis evaluating the duration of dexamethasone therapy. European Journal of Pediatrics $2005 \mathbf{1 6 4} 472-481$.

12 Ballard PL, Gluckman PD, Liggins GC, Kaplan SL \& Grumbach MM. Steroid and growth hormone levels in premature infants after prenatal betamethasone therapy to prevent respiratory distress syndrome. Pediatric Research 198014 122-127.

13 Watterberg KL, Gerdes JS, Cole CH, Aucott SW, Thilo EH, Mammel MC, Couser RJ, Garland JS, Rozycki HJ, Leach CL, Backstrom C \& Shaffer ML. Prophylaxis of early adrenal insufficiency to prevent bronchopulmonary dysplasia: a multicenter trial. Pediatrics 2004114 1649-1657.

14 Peltoniemi O, Kari MA, Heinonen K, Saarela T, Nikolajev K, Andersson S, Voutilainen R \& Hallman M. Pretreatment cortisol values may predict responses to hydrocortisone administration for the prevention of bronchopulmonary dysplasia in high-risk infants. Journal of Pediatrics 2005146 632-637.

15 Seckl JR. Prenatal glucocorticoids and long-term programming. European Journal of Endocrinology 2004151 U49-U62.

16 Falkenberg ER, Davis RO, DuBard M \& Parker CR Jr. Effects of maternal infections on fetal adrenal steroid production. Endocrine Research 199925 239-249.

17 Karlsson R, Kallio J, Toppari J, Scheinin M \& Kero P. Antenatal and early postnatal dexamethasone treatment decreases cortisol secretion in preterm infants. Hormone Research $2000 \mathbf{5 3}$ 170-176.

18 Ng PC, Lam CW, Lee CH, Ma KC, Fok TF, Chan IH \& Wong E. Reference ranges and factors affecting the human corticotropinreleasing hormone test in preterm, very low birth weight infants. Journal of Clinical Endocrinology and Metabolism 2002874621 4628.

19 Banks BA, Cnaan A, Morgan MA, Parer JT, Merrill JD, Ballard PL \& Ballard RA. Multiple courses of antenatal corticosteroids and outcome of premature neonates. North American ThyrotropinReleasing Hormone Study Group. American Journal of Obstetrics and Gynecology 1999181 709-717. 
20 Wilson DM, Baldwin RB \& Ariagno RL. A randomized, placebocontrolled trial of effects of dexamethasone on hypothalamicpituitary-adrenal axis in preterm infants. Journal of Pediatrics $1988113764-768$.

21 Rizvi ZB, Aniol HS, Myers TF, Zeller WP, Fisher SG \& Anderson CL. Effects of dexamethasone on the hypothalamic-pituitary-adrenal axis in preterm infants. Journal of Pediatrics $1992 \mathbf{1 2 0} 961-965$.

22 Kari MA, Heinonen K, Ikonen RS, Koivisto M \& Raivio KO. Dexamethasone treatment in preterm infants at risk for bronchopulmonary dysplasia. Archives of Disease in Childhood $199368566-569$.

23 Ford LR, Willi SM, Hollis BW \& Wright NM. Suppression and recovery of the neonatal hypothalamic-pituitary-adrenal axis after prolonged dexamethasone therapy. Journal of Pediatrics 1997 $131722-726$.

24 Ng PC, Wong GW, Lam CW, Lee CH, Fok TF, Wong MY, Wong W \& Chan DC. Pituitary-adrenal suppression and recovery in preterm very low birth weight infants after dexamethasone treatment for bronchopulmonary dysplasia. Journal of Clinical Endocrinology and Metabolism 199782 2429-2432.

25 Garland JS, Alex CP, Pauly TH, Whitehead VL, Brand J, Winston JF, Samuels DP \& McAuliffe TL. A three-day course of dexamethasone therapy to prevent chronic lung disease in ventilated neonates: a randomized trial. Pediatrics 1999104 91-99.

26 Sinkin RA, Dweck HS, Horgan MJ, Gallaher KJ, Cox C, Maniscalco WM, Chess PR, D'Angio CT, Guillet R, Kendig JW,
Ryan RM \& Phelps DL. Early dexamethasone-attempting to prevent chronic lung disease. Pediatrics 2000105 542-548.

27 Scott SM, Backstrom C \& Bessman S. Effect of five days of dexamethasone therapy on ventilator dependence and adrenocorticotropic hormone-stimulated cortisol concentrations. Journal of Perinatology 199717 24-28.

28 Kovacs L, Davis GM, Faucher D \& Papageorgiou A. Efficacy of sequential early systemic and inhaled corticosteroid therapy in the prevention of chronic lung disease of prematurity. Acta Paediatrica $199887792-798$.

29 Procianoy RS \& Cecin SK. The influence of labor and delivery on preterm fetal adrenal function. Acta Paediatrica Scandinavica 1985 74 400-404.

30 Procianoy RS, Giacomini CB \& Oliveira ML. Fetal and neonatal cortical adrenal function in birth asphyxia. Acta Paediatrica Scandinavica 198877 671-674.

31 Parker CR Jr, Favor JK, Carden LG \& Brown CH. Effects of intrapartum stress on fetal adrenal function. American Journal of Obstetrics and Gynecology 1993169 1407-1411.

32 Watterberg KL. Adrenocortical function and dysfunction in the fetus and neonate. Seminars in Neonatology 20049 13-21.

Received 9 November 2006

Accepted 14 February 2007 